Hernández Alvarado, Elizabeth. Ellas y yo. Identidades de papel. Madrid: Mercurio Editorial, 2018. ISBN 13: 9788494937156.

Este segundo libro de Elizabeth Hernández Alvarado -el primero, en la misma editorial, fue Pensando a gritos (2016) - no hace más que afianzar una pasión por la escritura que deviene, citando a Josefina Plá, «oficio de mujer» (1987 31-32). No es baladí esta imagen, ya que desde el mismo título nos enfrentamos a las identidades femeninas, confundidas-que no confusas-de «ellas y yo», en un claro juego de empatía y sororidad. Acaso el título también sorprende porque entrańa cierta ambigüedad o más bien una ironía cierta. Se pudiera pensar que «identidades de papel» albergan en sí mismas una contradicción. Si la identidad se entiende como conjunto de rasgos que caracterizan, en este caso a las mujeres, o como conciencia que una persona tiene de ella misma y distinta a las demás, pudiéramos creer que ese "de papel» le resta solidez. Mujeres de papel, algo así como de poca importancia, inútiles e inconsistentes, acaso porque nos trae ecos de aquella expresión que dice: "como el papel mojado". Al parecer este modismo lo usaban los fabulistas en el siglo XVII como fórmula para rematar el discurso, una especie de "colorín, colorado", pero en esa ocasión se finalizaba con "eran de papel, y mojóse y acabóse» (Montenegro 2006). Arturo Montenegro refiere que «los proverbios y modismos en torno al papel tienen un claro trasfondo legal» $y$ trae a colación una misiva que la gran Catalina de Rusia escribió al enciclopedista Diderot, en la cual señalaba lo siguiente:

Vos, sabio e ilustrado filósofo, expresáis con toda holgura y sin inconveniente alguno grandes pensamientos, porque trabajáis sobre el papel, materia unida y compacta que todo lo admite, sin resistirse ni presentar obstáculos ni a vuestra fantasía ni a vuestra pluma; mientras que yo, pobre emperatriz, he de trabajar sobre la piel humana, que, como vos sabéis, es irritable y descontentadiza en extremo (citado en Montenegro).

Trabajar «sobre la piel humana» frente a trabajar «sobre el papel», sugerente expresión que retomaremos más adelante para aludir a la estrategia escritural que guía a Elizabeth Hernández Alvarado.
Pero continuemos con esas «identidades de papel», porque dicen que «el papel todo lo aguanta", incluso los prejuicios o estereotipos. De ahí que dicha expresión también nos haga presuponer que las mujeres asumen sus identidades como si de un papel se tratase, una representación. Ya lo cantaba La Lupe, «la vida es puro teatro». Féminas-personajes en la dura función que es la vida. Judith Butler hablaría de "performatividad» (2007). En este sentido, las mujeres sabemos mucho de papeles, pues a lo largo de la Historia no nos han tocado los mejores, sobre el papel y en la práctica. Nos han considerado minoría, sin condición legal como las y los sin papeles. Nos han hecho perder los papeles en más de una ocasión. Hemos sido relegadas a un papel claramente secundario. Nos han querido dar un papel temático: buenas mujeres, buenas madres, buenas esposas. Nos han quebrado como al papel. Nos han tratado como papel pintado y, en ocasiones, nuestros derechos han devenido papel confeti. En épocas de crisis incluso hemos servido de intercambio como el papel moneda. Y, desde luego, nos han tachado de falsas, de tan falsas e inconsistentes como el papel mojado. Así que, aun cuando las cosas parecen estar cambiando, debemos convenir que hemos tenido un papel deslucido a lo largo de los siglos.

Es aquí, precisamente, cuando cobra verdadero sentido el título que nos ocupa: «Identidades de papel». Frente a lo que hemos señalado, en este libro se visibiliza un compendio de mujeres que no han aceptado el papel que les marcaron y que rechazaron mediante la pluma los estereotipos asignados. Ellas son las que rastreamos a lo largo de estas páginas, las que han dejado huellas y «componen el tronco del árbol milenario alrededor del que bailan todas las mujeres» (3), dirá nuestra autora. Como pórtico a esta obra y a esta conciencia se presentan las palabras de Laura Freixas, Todas llevan máscara. Diario 1995-1996 (2018) y de Virgine Despentes, Teoría King Kong (2006). Las ideas de esta última cobran hoy en día más fuerza, si pensamos que su obra, Teoría King Kong, vio la luz antes de lo que, sin duda, podemos llamar la gran revolución feminista de los últimos años, muy vinculada a los movimientos sociales, a las 
manifestaciones multitudinarias a nivel internacional, a la denuncia contra el acoso sexual y cualquier tipo de violencia o explotación contra las mujeres (Ni una menos, $\mathrm{Me}$ too). Para algunas esto viene a suponer la cuarta ola del feminismo, cuyo inicio se sitúa alrededor de 2012, y en la que la mujer se erige en sujeto político de pleno derecho (Miyares 2018). En este sentido, con anterioridad la escritora francesa Despentes abordaba el tema de la violencia sexogenérica, denunciando el hecho de cómo el inconsciente colectivo, a través de los instrumentos de poder de los medios de comunicación o de la industria cultural, establece valoraciones diferentes dependiendo del tipo de violencia y de quién la ejerza:

Los hombres denuncian con virulencia las injusticias sociales o raciales, pero se muestran indulgentes y comprensivos cuando se trata de la dominación machista. Son muchos los que pretenden explicar que el combate feminista es secundario, como si fuera un deporte de ricos, sin pertinencia ni urgencia. Hace falta ser idiota, o asquerosamente deshonesto, para pensar que una forma de opresión es insoportable y juzgar que la otra está llena de poesía (24).

Sin duda, por este motivo, albergando una clara conciencia feminista, Elizabeth Hernández Alvarado se acompaña en este viaje escritural de estas mujeres insurrectas y de ella misma, otra rebelde e inconformista, como las de su texto «Una vida plana» o «Eterna insatisfacción». "Ellas» $y$ «Yo», amalgamadas en un "todas las que yo era», parafraseando a Bernardo Ezequiel Koremblit (1991), quien así definió a Alejandra Pizarnik; estos son, pues, los epígrafes sobre los que se vertebra esta obra. Ambos se erigen en una declaración de principios:

Yo soy todas las mujeres, la niña inocente, la joven provocadora, la dama de cabellos blancos y mirada regia. La que tiene miedo, la que sabe las respuestas, la que se adapta y se miente, la que explota y vive, la que busca, la que se atreve, la que se culpa. Yo soy todas las mujeres, siempre lo fui. Ahora lo sé (75).

Un total de cuarenta y un textos que muestran una misma preocupación, indagar en el proceso literario: «la relación entre la realidad y la ficción como herramientas de trabajo en la literatura» (12), reconocerá. Llevada por este interés, afirmará desde el inicio que "cuando la vida pasa por el tamiz de la escritura, deja de ser vida y se convierte en literatura» (14). No olvidemos, ya lo decía Oscar Wilde, "que la Vida imita al arte mucho más de lo que el Arte imita a la vida» (50-51). Por este motivo, creemos que muy acertadamente, Elizabeth ha elegido el género discursivo de la crónica. Un registro a medio camino entre la realidad y la ficción, en el que todo cabe, incluso diarios, biografías y memorias, que tanto gustan a nuestra autora, acaso por eso mismo algunos escritores como Pedro Lemebel lo han denominado "género bastardo" o "prosa de no ficción", recordando la definición dada por Truman Capote al referirse a su obra $A$ sangre fría (1965). En los últimos tiempos se elevan voces, como la de Manuel Bartual, quien alude a la "posficción», término que cobra sentido en esta era de la posverdad en la que vivimos.

La crónica literaria le permite a Elizabeth Hernández Alvarado «trabajar sobre la piel», tal y como definía su labor Catalina de Rusia. Sobre y "con» la piel, pues en este proceso creativo nuestra autora se despoja, se desviste, se muestra tal y como es; revela sus dudas y sus miedos; nos desvela sus secretos más recónditos. Para ello se metamorfosea en la carne de esas otras que la habitan. Escribe y lee sobre mujeres, mujeres que escriben y leen sobre otras mujeres. En este acontecer sus textos devienen escritura a flor de piel. Pero no nos quedemos con la literalidad de esta expresión, tal como reclama Elizabeth Hernández Alvarado, trayendo a colación a Miguel Lorente y su reflexión sobre el uso del lenguaje inclusivo; literalidad que en este caso es metáfora. Porque estas crónicas nos hablan de la piel a través de la exploración del cuerpo de mujer, del suyo y el de sus pares, a partir de las experiencias más íntimas o de las más colectivas, en todas ellas vuelca sus visiones más personales. Miradas más críticas a veces, más intimistas otras, pero siempre urgidas por la necesidad de conocer desde dentro. Adentrándose, adentrándonos. Así la piel se transforma en papel. El papel en piel. Identidades de papel, obra sincera y descarnada, antítesis de ostentación. 


\section{REFERENCIAS BIBLIOGRÁFICAS}

Bartual, Manuel. "La posficción y cómo hemos llegado a ella». 5 de marzo de 2019. Centre de Cultura Contemporània de Barcelona (CCCBLAB). Edición en línea. <http://lab.cccb.org/ es/la-posficcion-y-como-hemos-llegado-a-ella/>. Consultado el 24 de mayo de 2019.

Butler, Judith. El Género en disputa. El feminismo y la subversión de la identidad. Trad. M. Antonia Muńoz. Barcelona: Paidós, 2007.

Despentes, Virgine. Teoría King Kong. Trad. Beatriz Preciado. Barcelona: Melusina, 2007 [2006].

Koremblit, Bernardo Ezequiel. Todas las que ella era. Ensayo sobre Alejandra Pizarnik. Buenos Aires: Corregidor, 1991.

Miyares, Luisa. "La 'Cuarta ola del feminismo', su Agenda». Tribuna feminista. 11 de marzo de 2018. Edición en línea. <https://tribunafeminista.elplural.com/2018/03/la-cuarta-ola-del-feminismosu-agenda/>. Consultado el 24 de mayo de 2019.
Montenegro, Arturo. "La frase «Esto es papel mojado"». Centro Virtual Cervantes. 23 de febrero de 2006. Edición en línea. <https://cvc.cervantes.es/el_rinconete/anteriores/febrero_06/23022006_01. htm>. Consultado el 23 de mayo de 2019.

Plá, Josefina. «Tiempo vestido de mujer». La llama y la arena. Asunción-Paraguay: Alcándara Editora, 1987, pp. 31-32.

Real Academia Española. Diccionario de la lengua española (23. ${ }^{a}$ ed.). 21 de octubre de 2015. Edición en línea. <http://www.rae.es/rae.html>. Consultado el 25 de octubre de 2018.

WILde, Oscar. La decadencia de la mentira. Trad. María Luisa Balseiro. Madrid, Siruela, 2000 [1889].

Ángeles Mateo del Pino

Universidad de Las Palmas de Gran Canaria DOI: https://doi.org/10.25145/j.clepsydra.2019.18.12 
